Article

\title{
Features of Humic Compound Sorption by Anion Exchangers
}

\author{
Nataliya MAKAROVA, Tetiana MITCHENKO, Andrey MITCHENKO, Helena SCHEVCHUK \\ Chemical Department, National Technical University of Ukraine, 37, Pr. Pobedy, Kiev, 03056, Ukraine \\ Gudrun ABBT-BRAUN \\ University of Karlsruhe, Engler-Bunte-Institute, Engler-Bunte-Ring 1, D-76131 Karlsruhe, Germany
}

(Manuscript submitted February 19, 2003; accepted April 16, 2003)

\begin{abstract}
The removal of humic compounds is an urgent task in tap water treatment in Ukraine. The use of polymeric recycled scavengers is most perspective for the purification of water up to the requirements needed for drinking and technical water. This study shows results for the extraction of the humic compounds from water by strong- and weak-base anion exchange resins with various porous structures. The results show that SDVBbase anion exchange resins Dowex 11, Dowex MSA-1 and Dowex MWA-1 are most effective. Studies were performed by static and dynamic conditions. Mechanism of the adsorption of humic compounds by anion exchange resins and the application for different tasks of water treatment were shown.
\end{abstract}

\section{Research and Discussion}

In Ukraine the removal of humic compounds (HC) from tap water is a severe problem during water treatment processes. Tap water is used for drinking water, and after further treatment in food industry, in electronic industry, power stations etc. The use of polymeric recycled scavengers is most perspective to purify the tap water. Using these resins the concentration of $\mathrm{HC}$ in water can be removed to a high extent (e.g.: oxidation by permanganate before treatment: 4-10 $\mathrm{mg} \mathrm{O}_{2} / \mathrm{dm}^{3}$, after treatment: $<2 \mathrm{mg} \mathrm{O}_{2} / \mathrm{dm}^{3}$ ).

Several types of anion-exchange resins can be used for the adsorption of HC from tap water. The types vary in the polymeric matrix nature, and in bases and porous structure. The ability of the resins to adsorb HC from tap water was compared by the determination of exchange capacity $\left(E^{\prime}\right)$, describing the amount of functional groups located in pores that twice large than the linear size of the prevailing fraction of $\mathrm{HC}$ molecules.[1] The molecular weight (MW) of $\mathrm{HC}$ was determined by gel chromatography combined with DOC detection (DOC: dissolved organic carbon; LC-DOC method).

The experiments were performed by dynamic conditions (volumetric velocity 10 bed volume per hour; BV/h) and model solutions ( $\mathrm{HC}$ content: $10 \mathrm{mg} \mathrm{O} / \mathrm{dm}^{3}$, oxidation with permanganate). The results have shown, that the gel anion exchange resins Dowex 11 (strong-base, styrene divinylbenzene) and Amberlite IRA 67 (weak-base, polyacrylic) have higher adsorption ability to $\mathrm{HC}$ compared to porous resins.

However, the use of anion exchange resins as scavengers is defined not only by a high adsorption of $\mathrm{HC}$, but also by the ability of being recyclable. Recycling has to be easy and up to a maximum of restoration of sorptionproperties by cheap and accessible regeneration agents. The efficiency of the regeneration of the anion exchange resins depends on the nature and the structure of the polymeric matrix of the adsorbents. 
The desorption of HC from polyacrylic anion exchange resins is difficult to perform.[2] Besides, the application of these adsorbents for drinking water purification is complicated by low stability of their polymeric matrix to influence of strong oxidizers (e.g., chlorine) and temperature, also raised amount of water for washing after alkaline regeneration. Due to the restrictions, three styrene divinylbenzene (SDVB) anion exchange resins were chosen for further studies: Dowex 11 (gel, strong-base), Dowex MSA-1 (macroporous, strong-base), and Dowex MWA-1 (macroporous, weak-base).

The results showing the selectivity of anion exchange resins to different molecular weight fractions of $\mathrm{HC}$ are presented in Fig. 1. It is obvious that Dowex 11 is the most effective adsorbent for the removal of all $\mathrm{HC}$ fractions from water. The removal of lower molecular weight fractions is worse for Dowex MSA-1. The sorption efficiency for of all

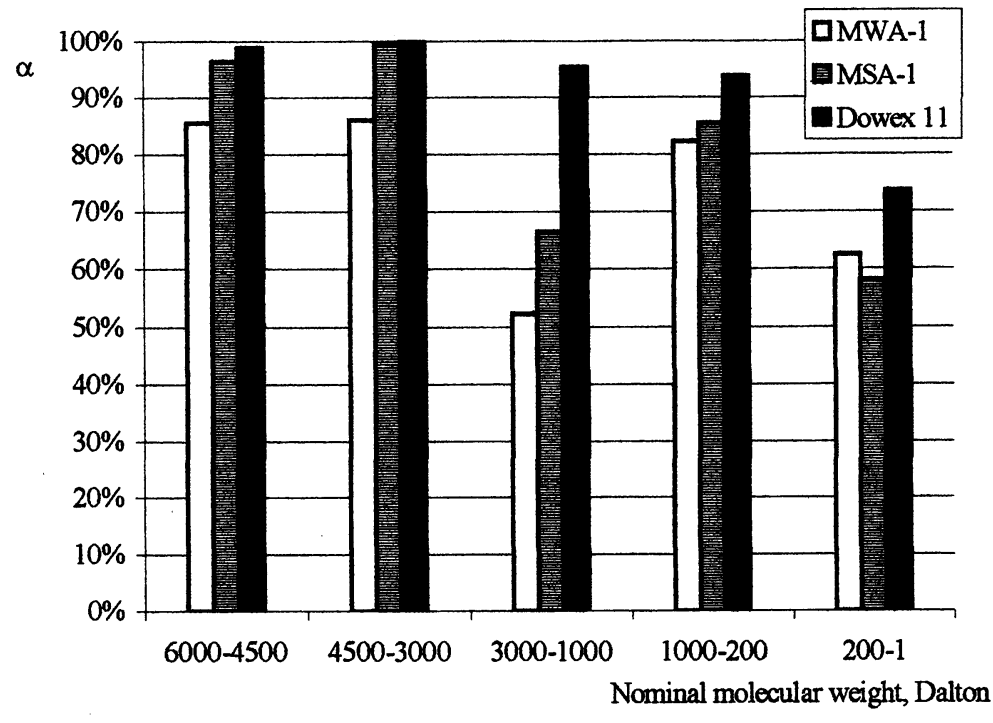

Fig. 1. The uptake $(\alpha)$ of $\mathrm{HC}$ fractions by anion exchange resins (at $H=10 \mathrm{mg} \mathrm{O}_{2} / \mathrm{cm}^{3}$ resin).

HC fractions using Dowex MWA-1 is much lower compared to the strong base anion resins.

For the preparation of drinking and beverage water the preservation of the mineral composition after treatment is the rather important.

The concentration of the anions (chlorides, sulphates and hydrocarbonates) is changing by using Dowex 11 (Fig. 2a). The composition of the minerals is changing less by using Dowex MWA-1 (Fig. 2b).
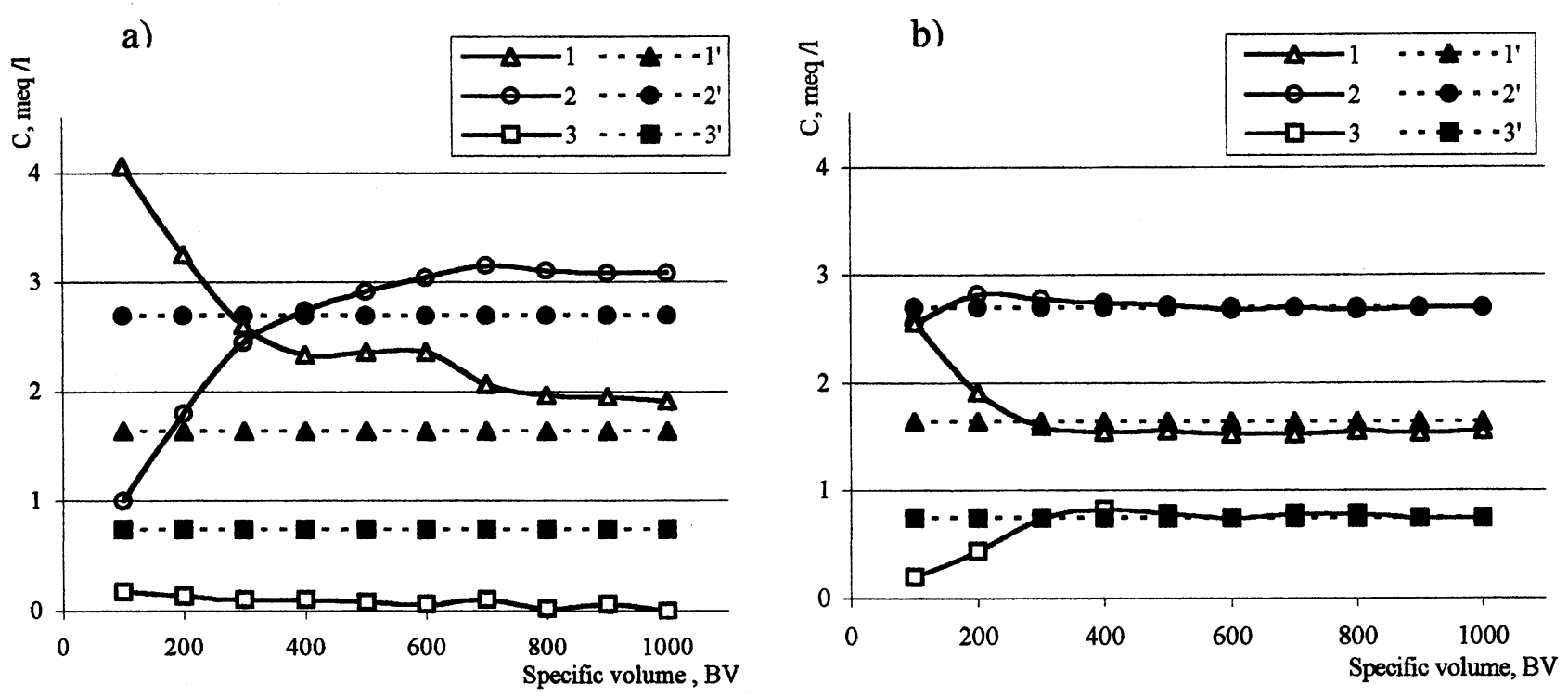

Fig. 2. Anions concentration before $\left(1^{\prime}, 2^{\prime}, 3^{\prime}\right)$ and during treatment $(1,2,3)$ by strong-base anion exchange resin Dowex 11 (a) and by weak-base anion exchange resin Dowex MWA-1 (b) (1, $1^{\prime}$ - chloride; $2,2^{\prime}$ - hydrocarbonate; $3,3^{\prime}$ - sulphate). 
The data show that Dowex MWA-1 can be considered for the removal of HC from tap water used for beverages. Dowex 11 and Dowex MSA-1 - can be used in industrial water treatment processes such as electric power industry and other manufactures.

To define the optimum conditions for $\mathrm{HC}$ adsorption by anion exchange resins the influence of the organic loading and volumetric velocity of the solution was investigated.

The maximum of organic loading $\left(H, \mathrm{mg} \mathrm{O} / \mathrm{cm}^{3}\right.$ resin) is convenient for the estimation of the filtration interval for scavengers. To define the allowable organic loading for Dowex 11 and Dowex MWA-1, dynamic experiments were performed with model solutions prepared on tap water of Kiev.

The data have shown, that $\mathrm{HC}$ fractions with molecular weight lower than 3000-100 Daltons are less removed using Dowex-MWA-1, if organic loading is more than $10 \mathrm{mg} \mathrm{O}_{2} / \mathrm{cm}^{3}$ resin. This might be due to a competitive replacement of smaller molecules by larger ones with molecular weight of 6000-4500 Daltons. Selective sorption of large organic molecules is carried out, apparently, due to greater specific density of functional groups in these molecules and additional Van-der-Waals interaction of hydrophobic sites with a polymeric matrix of adsorbent. Strong-base anion exchange resin Dowex 11 is rather effectively to remove the basic fractions of $\mathrm{HC}$ at organic loading up to $20 \mathrm{mg} \mathrm{O} / \mathrm{cm}^{3}$ resin. At the further increase of organic loading the replacement of fraction 3000-1000 Daltons by larger molecules (4500-3000 Daltons) also is characteristic for Dowex 11, however to a lesser extent, than for Dowex MWA-1.

The influence of the volumetric velocity of the solution, which passed through the adsorbent layer on the $\mathrm{HC}$ extraction by Dowex MWA-1 and Dowex 11, was investigated in addition. The results (Fig. 3) show, that the change of the solution volumetric velocity influences on the $\mathrm{HC}$ adsorption. The influence is higher for

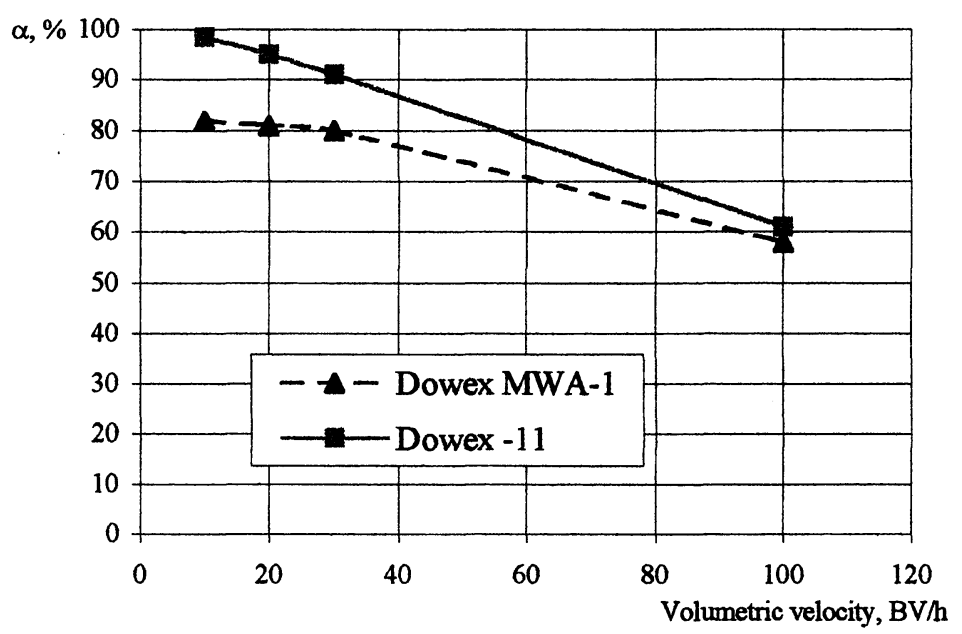

Fig. 3. Influence of the solution volumetric velocity on $\mathrm{HC}$ uptake $(\alpha, \%)$ (1000 BV of model solution was passed).

Dowex 11 than for Dowex MWA-1. If the volumetric velocity raises up to $100 \mathrm{BV} / \mathrm{h}$ the efficiency of $\mathrm{HC}$ adsorption is reduced appreciably and practically becomes equal.

Compared to the use of activated carbon for HC removal from water, anion exchange resins show higher capacities and the ability to work in a high cycle mode "sorption-regeneration". It is known, that solutions containing $2 \% \mathrm{NaOH}+10 \% \mathrm{NaCl}$ are the optimum regeneration agent for restoration its scavengers properties. [3] However, for purposes in drinking (or food) water purification $10 \%$ solution of $\mathrm{NaCl}$ are more preferred.

The efficiency of the regeneration process was studied in static and dynamic modes. For the experiments tap water from Kiev was used.

The data show that the application of alkaline sodium chloride for the regeneration of the resins influences differently on the sorption properties restoration. The regeneration of strong-base anion exchange resins by alkaline sodium chloride results in the best restoration of their sorption properties. Using a $\mathrm{NaCl}$ solution is worse. This can be explained by a partial transition resins to $\mathrm{OH}$-form having greater relationship to $\mathrm{HC}$ in comparison with the $\mathrm{Cl}^{-}$-form. On the other hand, the alkaline regeneration of Dowex MWA-1 results in an essential decrease of $\mathrm{HC}$ adsorption in following cycle, due to higher relationship to $\mathrm{OH}^{-}-$ions, than to $\mathrm{HC}$ molecules. 
The sorption ability of Dowex 11 and Dowex MWA-1 to HC in a long time operation was studied in the high cycle mode "sorption-regeneration". The anion exchange resins were regenerated by six $\mathrm{BV}$ of $10 \% \mathrm{NaCl}$ after passing $1000 \mathrm{BV}$ of model solution. Two series of experiments with 10 cycles in everyone were performed with a volumetric velocity of 20 and $100 \mathrm{BV} / \mathrm{h}$. The results have shown, that the sorption ability of the resins is reduced from cycle to cycle. The decrease for Dowex 11 was well over, compared to Dowex MWA-1. After cycle 10, the $\mathrm{HC}$ sorption for both exchange resins becomes comparable (while in the first cycle the HC uptake from solution by Dowex 11 was much higher, than by Dowex MWA-1). Similar data were received for Dowex MSA-1 also, but its regeneration degree was higher compared to the gel analogue.

\section{Results}

The executed researches have shown following:

- Dowex 11 (strong-base SDVB anion exchange resin) has the highest sorption capacity for HC investigated. Dowex MSA-1 (analogue macroporous resin) shows lower HC sorption, but by the best kinetic characteristics. Using the strong-base anion exchange resin for the removal of $\mathrm{HC}$, composition of the anions will be changed. Weak-base SDVB macroporous anion exchange resin Dowex MWA-1 is most perspective for HC removal from water, when it mineral contents should be kept.

- The exchange resins can be regenerated effectively by a solution containing $10 \% \mathrm{NaCl}+2 \% \mathrm{NaOH}$. However, this solution results in deterioration of water taste and smell. The weak-base anion exchange resins can be regenerated much effective by $\mathrm{NaCl}$ solution. The regeneration of gel anion exchange resins is complicated compared to macroporous resins. The sorption ability for strong-base anion exchange resins to HC is better after treatment by alkaline $\mathrm{NaCl}$ solution. For weak base resin, the sorption ability is much better using $\mathrm{NaCl}$ solution.

The following optimum conditions for operation with scavengers were received:

For strong-base anion exchange resins Dowex-11 and Dowex MSA-1:

- maximal $\mathrm{HC}$-loading during the filtration time $-20 \mathrm{mg} \mathrm{O}_{2} / \mathrm{cm}^{3}$ resin;

- $\mathrm{pH}-6-9$;

- regeneration by a solution containing $10 \% \mathrm{NaCl}$ and $2 \% \mathrm{NaOH}$. Herewith the desorption degree $85 \%$ for Dowex- 11 and $95 \%$ for macroporous Dowex MSA-1 is achieved;

- the solution volumetric velocity for gel anion exchange resin 20-30 BV/h, for macroporous anion exchange resin 20-60 BV/h.

For weak-base anion exchange resin Dowex MWA-1:

- maximal HC-loading $-10 \mathrm{mg} \mathrm{O} / \mathrm{cm}^{3}$ resin;

- $\mathrm{pH}-3-4$;

- regeneration by a solution containing $10 \% \mathrm{NaCl}$;

- the solution volumetric velocity $-20-100 \mathrm{BV} / \mathrm{h}$.

\section{Acknowledgement}

The investigations were sponsored by the INTAS ("Water Purification for Food Production", INTAS 00-174).

\section{References}

1) T.Y. Mitchenko, N.T. Kartel, A.A. Mitchenko, H.A. Shevchuk, Proceedings of the Intern.Conf. "Carbon 99", USA, 700-701 (1999).

2) A.V. Mamchenko, M.S. Novojenuk, H.V. Kryjanovskaya, Khimiya i tekhnologiya vody, 2, 136-142, (1997).

3) A.V. Mamchenko, Khimiya i tekhnologiya vody, 4, 270-294, (1993). 